\title{
Long-term rates of change in musculoskeletal aging and body composition: findings from the Health, Aging and Body Composition Study
}

\author{
Leo D. Westbury ${ }^{1}$. Holly E. Syddall ${ }^{1}$ Nicholas R. Fuggle ${ }^{1}$. Elaine M. Dennison ${ }^{1,2}$ - Jane A. Cauley ${ }^{3}$ Eric J. Shiroma ${ }^{4}$. \\ Roger A. Fielding ${ }^{5}$ Anne B. Newman ${ }^{3}$. Cyrus Cooper ${ }^{1,6,7}$
}

Received: 18 December 2019 / Accepted: 19 February 2020 / Published online: 3 March 2020

(c) The Author(s) 2020

\begin{abstract}
Musculoskeletal disorders are common among older people. Preventive strategies require understanding of age-related changes in strength, function and body composition, including how they interrelate. We have described, and examined associations between, 9-year changes in these parameters among 2917 Health, Aging and Body Composition Study participants (aged 70-79 years). Appendicular lean mass (ALM), whole body fat mass and total hip BMD were ascertained using DXA; muscle strength by grip dynamometry; and muscle function by gait speed. For each characteristic annualised percentage changes were calculated; measures of conditional change (independent of baseline) were derived and their interrelationships were examined using Pearson correlations; proportion of variance at 9-year follow-up explained by baseline level was estimated; and mean trajectories in relation to age were estimated using linear mixed models. Analyses were stratified by sex. Median [lower quartile, upper quartile] annual percentage declines were grip strength $(1.5[0.0,2.9])$, gait speed (2.0 $[0.6,3.7])$, ALM $(0.7[0.1,1.4])$, fat mass $(0.4[-1.1,1.9])$ and hip BMD $(0.5[0.0,1.1])$. Declines were linear for ALM and accelerated over time for other characteristics. Most conditional change measures were positively correlated, most strongly between ALM, fat mass and hip BMD $(r>0.28)$. Proportion of variation at follow-up explained by baseline was lower for grip strength and gait speed (39-52\%) than other characteristics (69-86\%). Strength and function declined more rapidly, and were less correlated between baseline and follow-up, than measures of body composition. Therefore, broader intervention strategies to prevent loss of strength and function in later life are required as those targeting body composition alone may be insufficient.
\end{abstract}

Keywords Epidemiology $\cdot$ Sarcopenia $\cdot$ Osteoporosis $\cdot$ Frailty $\cdot$ Muscle

Electronic supplementary material The online version of this article (https://doi.org/10.1007/s00223-020-00679-2) contains supplementary material, which is available to authorized users.

Cyrus Cooper

cc@mrc.soton.ac.uk

1 MRC Lifecourse Epidemiology Unit, University of Southampton, Southampton, UK

2 Victoria University of Wellington, Wellington, New Zealand

3 Department of Epidemiology, Graduate School of Public Health, University of Pittsburgh, Pittsburgh, USA

4 Laboratory of Epidemiology and Population Sciences, Intramural Research Program, National Institute on Aging, Baltimore, USA
5 Nutrition, Exercise Physiology, and Sarcopenia Laboratory, Jean Mayer USDA Human Nutrition Research Center on Aging, Tufts University, Boston, USA

6 NIHR Southampton Biomedical Research Centre, University of Southampton and University Hospital Southampton NHS Foundation Trust, Southampton, UK

7 NIHR Oxford Biomedical Research Centre, University of Oxford, Oxford, UK 


\section{Introduction}

Musculoskeletal disorders are common among older people and are a leading cause of morbidity worldwide [1]. Sarcopenia, the loss of muscle mass and strength with age, is associated with increased risk of disability and mortality and significant healthcare costs [2-4]. Annual direct medical costs attributable to sarcopenia were estimated at $\$ 18.5$ billion in the United States in 2000 [5] and annual excess health and social care costs associated with muscle weakness were estimated at $£ 2.5$ billion in a recent UK study [6]. Although there is no consensus definition of sarcopenia, most criteria use measures of grip strength, gait speed and lean mass. Sarcopenia is now regarded as a disease according to the International Classification of Diseases [7].

Another common musculoskeletal disorder is osteoporosis, characterised by low bone density and micro-architectural deterioration of bone tissue, which increases bone fragility [8]. Osteoporotic fractures are associated with increased risk of morbidity and mortality [9], resulting in huge individual and societal costs; the economic burden associated with osteoporotic fractures was estimated at $€ 37.4$ billion in the European Union in 2010 [10].

In addition to declines in lean mass and bone density, age-related changes in body composition include increases in fat mass, particularly in the abdominal area [11]. In general, increased fat mass in older age is related to increased risk of physical disability [12] and all-cause mortality [13], although some protective effects of being moderately overweight $(25 \leq$ body mass index $[\mathrm{BMI}]<30)$ have been reported in relation to mortality in meta-analyses $[14,15]$. However, large studies accounting for smoking and diseases causing weight loss have identified obesity $(\mathrm{BMI} \geq 30)$ and central-adiposity, indicated by greater waist-to-hip ratio, as risk factors for mortality, coronary heart disease and type 2 diabetes [16, 17]. Age-related reductions in lean mass in combination with increases in fat mass can result in the development of sarcopenic obesity, resulting in more adverse health effects than sarcopenia or obesity in isolation [18].

Preventive strategies for musculoskeletal disorders require a better understanding of age-related changes in muscle strength, physical function and body composition (including bone) as well as how these changes interrelate; from a public health perspective, this knowledge could inform the development of interventions to delay adverse changes in musculoskeletal aging. Previous research has established the following: aging is associated with declines in muscle mass, strength, physical function and bone density [19]; declines are greater for muscle strength and physical function compared to muscle mass [20,21]; and changes in some muscle and bone parameters are correlated [22]. However, to our knowledge, no studies have explored changes in both key sarcopenia components (muscle mass, strength and function) and aspects of body composition (muscle mass, fat mass and bone density) among a single cohort of older people in whom parameters have been measured at multiple time-points. To address this, we have described, and examined associations between, changes in musculoskeletal and body composition parameters among participants in the Health, Aging and Body Composition (Health ABC) Study, USA.

\section{Methods}

\section{The Health, Aging and Body Composition Study}

The Health ABC Study comprises 3075 US men and women (aged 70-79 years at baseline) who were recruited in 1997-1998. A random sample of white and of all of the black Medicare beneficiaries from around Memphis (Tennessee) and Pittsburgh (Pennsylvania) was obtained. Sampled participants received a mailing followed by a telephone eligibility screen. Individuals reporting no difficulty in walking one quarter of a mile or climbing 10 stairs were eligible. Individuals with the following characteristics were excluded: inability to communicate with the interviewer; clear cognitive impairment; having a life-threatening illness or difficulties with activities of daily living (ADL); requiring a walking aid; having an intention of moving outside the area within three years; or currently enrolled in a lifestyle intervention trial. Written, informed consent was provided by all participants and the study was approved by the institutional review boards at the University of Tennessee and the University of Pittsburgh.

\section{Ascertainment of Participant Characteristics}

The study methodology has been described in detail previously [23]. In brief, at baseline (Year 1), sex, race, educational attainment, and health behaviours such as smoking status and alcohol consumption were self-reported using questionnaires. Height and weight were measured using a Harpenden Stadiometer (Holtain Ltd, Crosswell, UK) and a standard balance beam scale, respectively. Physical activity was calculated using an instrument derived from the Leisure Time Physical Activity Questionnaire [24]. Approximate metabolic equivalent unit values were assigned to reported activities and intensity levels to derive caloric expenditure in $\mathrm{kcal} / \mathrm{kg} / \mathrm{h}$ [25]. Total kilocalories expended per week in stair climbing, walking and exercise activity, calculated by multiplying caloric expenditure by the participant's weight $(\mathrm{kg})$, was used as a measure of physical activity. Participants 
with $<1000 \mathrm{kcal} /$ week were regarded as having low physical activity [26]. Participants were asked whether a doctor had ever told them that they had various medical conditions. For this analysis, number of comorbidities was calculated out of the following: stroke, diabetes, Parkinson's disease, chronic obstructive pulmonary disease, heart attack or myocardial infarction, congestive heart failure and hypertension.

At Year 2, dietary intake over the previous year was assessed using a nurse-administered food frequency questionnaire (FFQ) comprising 108 items. To assess the extent to which Health $\mathrm{ABC}$ participants' diets conformed to recommendations of the Dietary Guidelines for Americans of 1995 and the Food Guide Pyramid of 1992, a healthy eating index (HEI), ranging from 0 to 100, was calculated for each participant; higher scores reflected healthier diets [27]. Poor diet quality was defined as scores $<51$ [28]. More information on the components of this HEI has been published previously [28].

Grip strength was measured two times for each hand at Years 1, 2, 4, 6, 8 and 10 using a Jamar dynamometer according to a standardised protocol throughout all stages of follow-up; maximum grip strength at each time-point was used for analyses. Grip strength values were set to missing for participants with severe hand pain or recent surgery. The calibration of the dynamometers was checked regularly. Customary gait speed was ascertained at Years 2, 3, 4, 5, 6, 8 and 10 by asking participants to walk at their normal speed down a corridor over a total distance of $20 \mathrm{~m}$. Whole-body dual-energy X-ray absorptiometry scans (Hologic QDR 4500A; Hologic, Bedford, MA, USA) were performed at Years 1, 2, 3, 4, 5, 6, 8 and 10 and used to ascertain whole body fat and appendicular lean mass (ALM) in $\mathrm{kg}$. Total hip $\mathrm{BMD}$, a repeatable measurement that is predictive of future fracture, was measured using the same device at Years 1, 3, 5,8 and 10 . The reproducibility and validity of this scanner has been previously reported $[29,30]$. Regular DXA phantom scans were performed for quality control and calibration purposes.

\section{Statistical Methods}

Baseline participant characteristics were described using means and standard deviations (SD), medians and interquartile ranges, or frequency and percentage distributions as appropriate. Normality of the following five characteristics was confirmed through visual inspection of histograms: grip strength, gait speed, ALM, whole-body fat mass and hip BMD. The statistical methods that were applied to each of these five characteristics are stated below. Firstly, percentage change since baseline was calculated at each time-point and person-specific linear regression models were used to model percentage change since baseline on age at each time-point; a participant's estimated annual percentage change is given by the regression coefficient for age. Pairwise comparisons of the mean and variance for each characteristic were performed using t-tests and variance ratio tests, respectively. Second, conditional change (independent of baseline) was characterised by obtaining the residuals from sex-specific linear regression models for characteristics at follow-up (Year 10) on baseline characteristics with adjustment for individual follow-up duration. The proportion of variance at Year 10 that was explained by baseline level and conditional change was estimated. Relationships between conditional change measures, including conditional change in weight from baseline to follow-up, were examined using Pearson correlations. Finally, the mean trajectory in relation to age was estimated using linear mixed effects models with random intercepts and slopes; quadratic and cubic age terms were included as fixed effects if significant $(p<0.05)$.

All analyses were stratified by sex and based on the sample of 2917 Health ABC participants with data on at least one of the characteristics (grip strength, gait speed, ALM, whole-body fat mass and hip BMD) at two or more timepoints. Sensitivity analyses included stratification by race as well as sex and, for each characteristic, a comparison of mean trajectories from participants with observations at all time-points as opposed to a minimum of two time-points. Analyses were conducted using Stata, release 15 (StataCorp, College Station, TX, USA).

\section{Results}

\section{Baseline Participant Characteristics}

Baseline participant characteristics among the analysis sample of 2917 Health ABC participants according to sex and race are presented in Table 1. Mean and standard deviation (SD) for age was 74.1 (2.9) years. A higher proportion of men were current drinkers and had post-secondary education compared to women $(p<0.001)$; prevalence of current smoking did not differ by sex $(p=0.29)$. Among both sexes, a higher proportion of black participants were current smokers but a lower proportion were current drinkers compared to white participants $(p \leq 0.001)$; having a post-secondary education was less common among black participants $(p<0.001)$. Regarding the musculoskeletal measures of interest, women had higher fat mass but all other measures were greater among men ( $p<0.001$ for all associations). Although both black men and women had slower gait speed compared to their white counterparts and black men had lower fat mass, the remaining measures were greater among black participants.

Compared to the 158 participants who were not included in the analytical sample, both men and women in the analytical sample were more likely to be white and 
Table 1 Baseline participant characteristics according to sex and race

\begin{tabular}{|c|c|c|c|c|c|c|}
\hline \multirow[t]{2}{*}{ Characteristic [Mean (SD) or $N(\%)$ ] } & \multicolumn{3}{|l|}{ Men } & \multicolumn{3}{|l|}{ Women } \\
\hline & White $(n=907)$ & Black $(n=511)$ & All $(n=1418)$ & White $(n=823)$ & Black $(n=676)$ & All $(n=1499)$ \\
\hline Age (years) & $74.4(2.9)$ & $74.0(2.7)$ & $74.2(2.8)^{* \dagger}$ & $74.1(2.8)$ & $73.8(2.9)$ & $74.0(2.9)^{* \dagger}$ \\
\hline Height (m) & $1.74(0.06)$ & $1.73(0.07)$ & $1.73(0.07)^{*}$ & $1.59(0.06)$ & $1.60(0.06)$ & $1.60(0.06)^{*}$ \\
\hline Weight (kg) & $81.4(12.4)$ & $81.3(14.3)$ & $81.4(13.1)^{*}$ & $66.1(12.1)$ & $75.7(15.8)$ & $70.4(14.6)^{* \dagger}$ \\
\hline BMI $\left(\mathrm{kg} / \mathrm{m}^{2}\right)$ & $27.0(3.7)$ & $27.1(4.3)$ & $27.0(3.9)^{*}$ & $26.0(4.5)$ & $29.7(5.9)$ & $27.6(5.5)^{* \dagger}$ \\
\hline Current smoker & $45(5.0 \%)$ & $106(20.7 \%)$ & $151(10.7 \%)^{\dagger}$ & $59(7.2 \%)$ & $83(12.3 \%)$ & $142(9.5 \%)^{\dagger}$ \\
\hline Current drinker & $582(64.5 \%)$ & $233(46.0 \%)$ & $815(57.8 \%)^{* \dagger}$ & $432(52.6 \%)$ & $204(30.2 \%)$ & $636(42.5 \%)^{* \dagger}$ \\
\hline Low physical activity & $468(51.6 \%)$ & $373(73.0 \%)$ & $841(59.3 \%)^{* \dagger}$ & $608(73.9 \%)$ & $560(82.8 \%)$ & $1168(77.9 \%)^{* \dagger}$ \\
\hline Poor diet quality ${ }^{\alpha}$ & $46(5.3 \%)$ & $63(14.0 \%)$ & $109(8.2 \%)^{\dagger}$ & $39(5.0 \%)$ & $49(8.3 \%)$ & $88(6.4 \%)^{\dagger}$ \\
\hline Number of comorbidities ${ }^{+}$ & $1(0,1)$ & $1(0,2)$ & $1(0,1)^{\dagger}$ & $0(0,1)$ & $1(0,1)$ & $1(0,1)^{\dagger}$ \\
\hline Post-secondary education & $546(60.3 \%)$ & $134(26.3 \%)$ & $680(48.0 \%)^{* \dagger}$ & $395(48.1 \%)$ & $181(26.9 \%)$ & $576(38.6 \%)^{* \dagger}$ \\
\hline Grip strength (kg) & 39.7 (7.7) & $42.8(8.7)$ & $40.8(8.2)^{* \dagger}$ & $23.6(5.1)$ & $26.6(6.2)$ & $25.0(5.8)^{* \dagger}$ \\
\hline Gait speed (m/s) & $1.23(0.19)$ & $1.10(0.20)$ & $1.19(0.21)^{* \dagger}$ & $1.16(0.19)$ & $1.01(0.20)$ & $1.09(0.21)^{* \dagger}$ \\
\hline ALM (kg) & $23.3(3.2)$ & $25.0(3.9)$ & $23.9(3.6)^{* \dagger}$ & $15.3(2.4)$ & $18.2(3.2)$ & $16.6(3.1)^{* \dagger}$ \\
\hline Fat mass (kg) & $24.7(6.9)$ & $23.2(7.4)$ & $24.2(7.1)^{* \dagger}$ & $27.0(7.9)$ & $31.6(10.2)$ & $29.1(9.3)^{* \dagger}$ \\
\hline Hip BMD $\left(\mathrm{g} / \mathrm{cm}^{2}\right)$ & $0.94(0.14)$ & $1.02(0.15)$ & $0.97(0.15)^{* \dagger}$ & $0.77(0.13)$ & $0.86(0.15)$ & $0.81(0.15)^{* \dagger}$ \\
\hline
\end{tabular}

$S D$ standard deviation, $A L M$ appendicular lean mass, $B M D$ bone mineral density

*Statistically significant sex differences $(p<0.05)$

${ }^{\dagger}$ Statistically significant racial differences within sex $(p<0.05)$

${ }^{\alpha}$ Ascertained at Year 2

${ }^{+}$Median (lower quartile, upper quartile) number of the following conditions (ever told by doctor): stroke, diabetes, Parkinson's disease, chronic obstructive pulmonary disease, heart attack or myocardial infarction, congestive heart failure and hypertension

have post-secondary education $(p<0.004)$; mean baseline grip strength was higher among men $(p=0.003)$ but there were no significant differences in the remaining musculoskeletal and body composition parameters at baseline among men or women.

\section{Percentage Change in Characteristics}

Boxplots of estimated annual percentage change in each characteristic are shown in Fig. 1. Among both men and women, mean percentage declines in grip strength and gait speed were greater than for all other characteristics $(p<0.02$ for all comparisons). Furthermore, variation in annual percentage decline in grip strength, gait speed and fat mass was greater than for ALM and hip BMD $(p<0.001$ for all comparisons according to variance ratio tests).

\section{Mean Trajectories of Characteristics}

Mean trajectories of characteristics for men and women are presented in Fig. 2. Decline in grip strength, gait speed and hip BMD accelerated somewhat with age; decline in ALM was linear. Fat mass increased, plateaued and then decreased

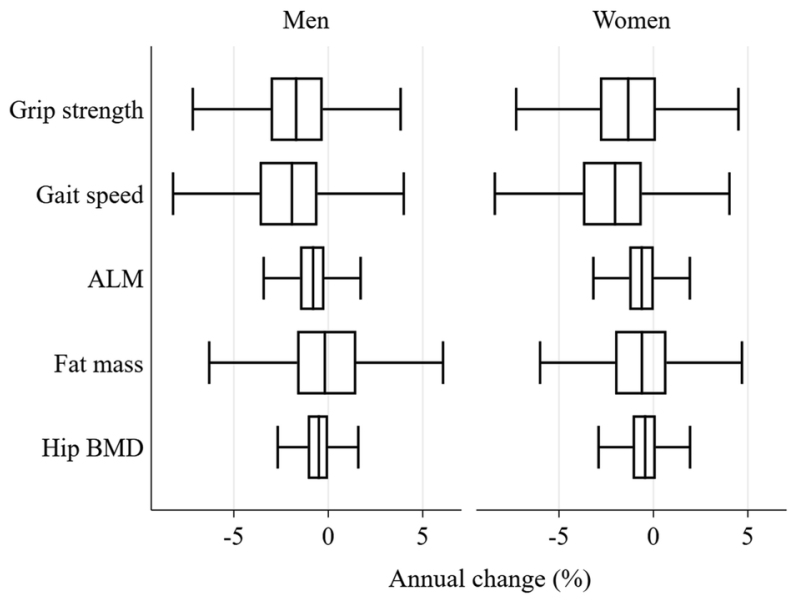

Fig. 1 Estimated annual percentage change in characteristics among men and women. Median annual changes (\%): grip strength -1.5 , gait speed -2.0; ALM -0.7; fat mass - 0.4; hip BMD -0.5. ALM appendicular lean mass, $B M D$ bone mineral density. The three vertical lines in the box represent the lower quartile (Q1), median and upper quartile $(\mathrm{Q} 3)$. The lower whisker is the smallest value that is greater than $\mathrm{Q} 1-1.5 \times \mathrm{IQR}$ and the upper quartile is the largest value which is less than $\mathrm{Q} 3+1.5 \times \mathrm{IQR}$, where $\mathrm{IQR}=\mathrm{Q} 3-\mathrm{Q} 1$. Estimates of percentage change for each participant were derived using personspecific linear regression models for percentage change since baseline calculated at each time-point as the outcome with age at each timepoint as the only predictor. Annual percentage change is given by the regression coefficient for age. Analysis was restricted to 1418 men and 1499 women with data on at least one change measure 

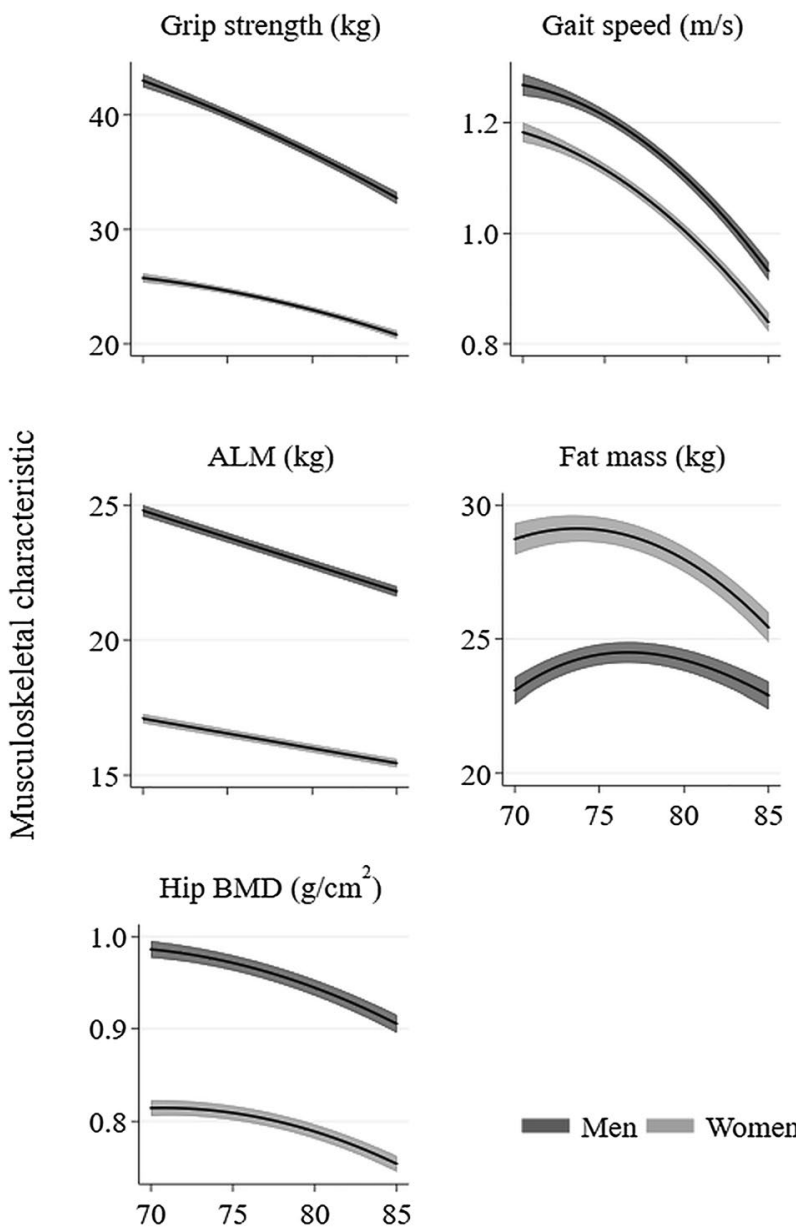

Age (years)

Fig. 2 Mean (95\% CI) trajectories of characteristics among men and women. ALM appendicular lean mass, BMD bone mineral density. Mean trajectories were derived using linear mixed effects models with random intercepts and slopes. Quadratic and cubic age terms were included as fixed effects if significant $(p<0.05)$. For each characteristic, trajectories from participants with at least two observations were included among men, whereas the initial period of increase was negligible among women.

\section{Proportion of Variation in Characteristics at Follow-Up Explained by Baseline Level and Conditional Change}

The proportion of variation in each characteristic at followup (Year 10) which was explained by baseline level and conditional change is shown in Fig. 3. Among both sexes, a substantial proportion of the variation (48-61\%) in grip strength and gait speed at Year 10 was explained by conditional change since baseline, whereas for other characteristics, this figure was only $14-31 \%$. Equivalently, the correlations between baseline and follow-up measurements were lower for grip strength and gait speed in comparison with the other characteristics.

\section{Correlations Between Changes in Characteristics}

Pearson correlations between conditional change measures for each characteristic are presented in Table 2; most were significantly positively correlated $(p<0.05)$, suggesting that declines in muscle strength, physical function and body composition parameters tend to co-occur. Changes in ALM, fat mass and hip BMD were correlated with one another among both sexes ( $r>0.28$ for all correlations); correlations between changes in fat mass and hip BMD were stronger among women $(r=0.47)$ than men $(r=0.29)$. Changes in grip strength and ALM were moderately correlated among men $(r=0.29, p<0.001)$ and women $(r=0.20, p<0.001)$. Among men and women, changes in weight and fat mass were very highly correlated $(r>0.89, p<0.001)$ and weight change in relation to changes in ALM and hip BMD were correlated $(0.40<r<0.74, p<0.001)$.
Fig. 3 Proportion of variance at follow-up (Year 10) explained by baseline level and conditional change since baseline. $A L M$ appendicular lean mass, $B M D$ bone mineral density. Measures of conditional change were derived using a residual change method and were independent of baseline level. Analyses restricted to 735 men and 864 women with data on at least one conditional change measure

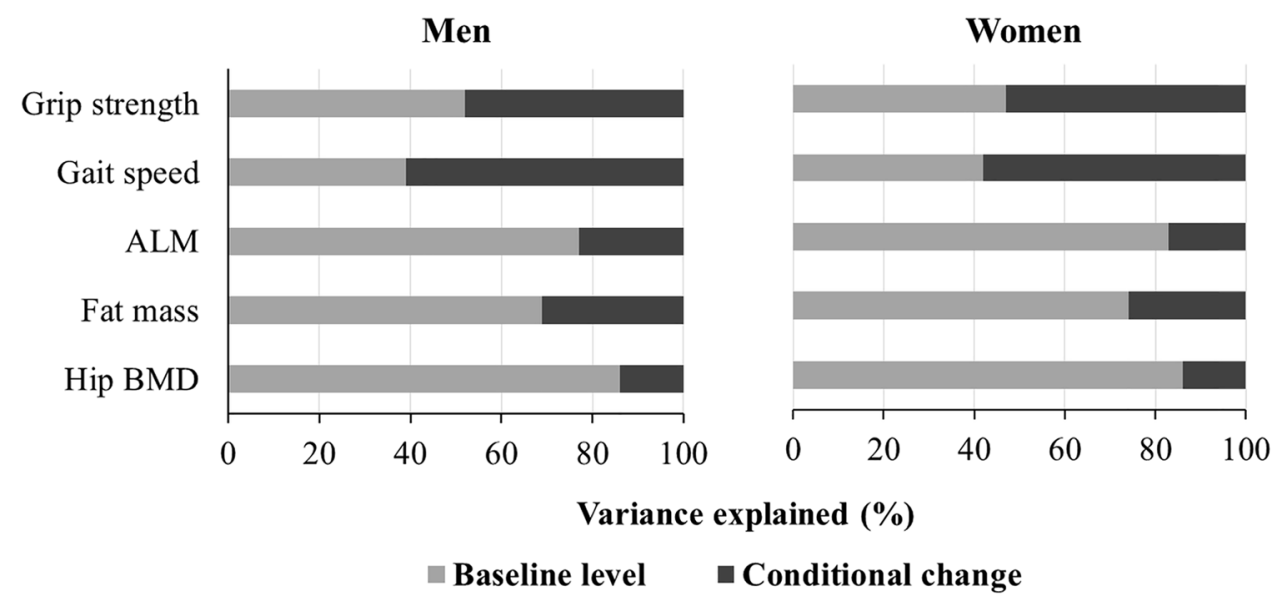

Men

Conditional change 
Table 2 Pearson correlations between conditional change measures among men and women

\begin{tabular}{llllll}
\hline Men & $\begin{array}{l}\text { Grip } \\
\text { strength }\end{array}$ & Gait speed & ALM & Fat mass & Hip BMD \\
\hline Gait & $\mathbf{0 . 1 4}$ & & & & \\
speed & & & & & \\
$p$-value & $<\mathbf{0 . 0 0 1}$ & & & & \\
ALM & $\mathbf{0 . 2 9}$ & 0.07 & & & \\
$p$-value & $<\mathbf{0 . 0 0 1}$ & 0.072 & & & \\
Fat mass & $\mathbf{0 . 0 9}$ & 0.05 & $\underline{\mathbf{0 . 4 5}}$ & & \\
$p$-value & $\mathbf{0 . 0 2 0}$ & 0.234 & $\underline{\mathbf{0 . 0 0 1}}$ & & \\
Hip BMD & $\mathbf{0 . 2 7}$ & $\mathbf{0 . 2 4}$ & $\underline{\mathbf{0 . 3 6}}$ & $\mathbf{0 . 2 9}$ & \\
$p$-value & $<\mathbf{0 . 0 0 1}$ & $<\mathbf{0 . 0 0 1}$ & $\leq \mathbf{0 . 0 0 1}$ & $\leq \mathbf{0 . 0 0 1}$ & \\
Weight & $\mathbf{0 . 1 9}$ & $\mathbf{0 . 0 9}$ & $\underline{\mathbf{0 . 7 3}}$ & $\underline{\mathbf{0 . 9 0}}$ & $\underline{\mathbf{0 . 4 1}}$ \\
$p$-value & $<\mathbf{0 . 0 0 1}$ & $\mathbf{0 . 0 2 4}$ & $\underline{\mathbf{0 . 0 0 1}}$ & $\leq \underline{\mathbf{0 . 0 0 1}}$ & $\leq \underline{\mathbf{0 . 0 0 1}}$ \\
Women & & & & & \\
Gait & $\mathbf{0 . 1 7}$ & & & & \\
speed & & & & & \\
$p$-value & $<\mathbf{0 . 0 0 1}$ & & & & \\
ALM & $\mathbf{0 . 2 0}$ & $\mathbf{0 . 0 8}$ & & & \\
$p$-value & $<\mathbf{0 . 0 0 1}$ & $\mathbf{0 . 0 2 4}$ & & & \\
Fat mass & $\mathbf{0 . 1 2}$ & 0.06 & $\underline{\mathbf{0 . 4 6}}$ & & \\
$p$-value & $<\mathbf{0 . 0 0 1}$ & 0.086 & $\underline{\mathbf{0 . 0 0 1}}$ & & \\
Hip BMD & $\mathbf{0 . 1 7}$ & $\mathbf{0 . 1 9}$ & $\underline{\mathbf{0 . 3 3}}$ & $\underline{\mathbf{0 . 4 7}}$ & \\
$p$-value & $<\mathbf{0 . 0 0 1}$ & $<\mathbf{0 . 0 0 1}$ & $\underline{\mathbf{0 . 0 0 1}}$ & $\leq \mathbf{0 . 0 0 1}$ & \\
Weight & $\mathbf{0 . 1 7}$ & 0.07 & $\underline{\mathbf{0 . 6 6}}$ & $\underline{\mathbf{0 . 9 4}}$ & $\underline{\mathbf{0 . 5 0}}$ \\
$p$-value & $<\mathbf{0 . 0 0 1}$ & 0.057 & $\underline{\mathbf{0 . 0 0 0 1}}$ & $\leq \mathbf{0 . 0 0 1}$ & $\leq \mathbf{0 . 0 0 1}$ \\
\hline
\end{tabular}

$B M D$ bone mineral density, $A L M$ appendicular lean mass

Participants with at least two conditional change measures (735 men and 863 women) were included; pairwise correlations are displayed

Change measures were derived using a residual change method and are independent of baseline level

Significant correlations $(p<0.05)$ are in bold; correlations where $r>0.3$ are in bold and underlined

\section{Sensitivity Analyses}

Results were broadly similar between races as shown in the Supplementary Material. Racial differences in mean trajectories were larger regarding levels of the characteristics rather than in rates of change (eFigure 2 in Online Resource).

Participants with complete data had mean trajectories with slightly higher initial levels and/or somewhat lower rates of decline regarding grip strength, gait speed and hip BMD compared to participants with data at two or more time-points (eFigure 4 in Online Resource). However, the broad changes in the characteristics were similar among both groups of participants.

\section{Discussion}

Among participants in the Health ABC Study, we have described, and examined associations between, changes in muscle strength, physical function and body composition parameters during a 9-year follow-up in later life. Declines in grip strength, gait speed and hip BMD accelerated somewhat with advancing age, whereas declines in ALM were linear. Declines were greater, and the proportion of variance at follow-up explained by baseline level was lower, for grip strength and gait speed in comparison with ALM, fat mass and hip BMD.

Our findings are consistent with those from previous analyses of the Health ABC Study. For example: over a 3-year follow-up, declines in knee extensor strength and both total and leg lean mass were correlated, although the absolute average magnitude of decline was greater for strength than mass [31]; 5-year declines in leg muscle torque were greater than those for muscle cross-sectional area [32]; and fat mass increased, plateaued and then decreased in a previous study of 5-year changes in body composition [33]. The latter suggests an initial trade-off between losing lean mass and gaining fat mass among weight-stable participants, followed by losses in weight, lean mass and fat mass with positive correlations between declines in weight and lean mass [34, 35]. Therefore, our analyses provide a longer term validation of these earlier findings.

Other cohorts have also described and compared longitudinal changes in muscle strength, physical function and body composition among older people. Our findings are in agreement with those from the Hertfordshire Cohort Study [20] and a cohort comprising 3018 Chinese participants, aged 65 and older [21], in which percentage declines in grip strength and gait speed were greater than declines in muscle mass. Although decline in grip strength curvilinearly accelerated with advancing age in the Health ABC Study, in a cohort comprising 8342 Danes (aged 50-85 years), linear declines in grip strength were observed [36] and in the Newcastle 85+ Study, grip strength decline was linear among men but quadratic among women [37]. A possible explanation for these conflicting results is the different age ranges and follow-up times of participants in these studies. Similar to our analyses, declines in grip strength and gait speed accelerated with advancing age among participants in the Cardiovascular Health Study [38] and this was also the case for total femoral neck BMD in the Osteoporotic Fractures in Men (MrOS) Study [39].

Previous studies have also examined interrelationships between changes in muscle strength, function and body composition. Changes in muscle strength and function in relation to changes in BMD among adults and children have been reported in a recent systematic review and meta-analysis 
[22]. Among adults, declines in BMD and the following characteristics were significantly correlated $(p<0.05)$ : lean mass ( $r=0.34$ [95\% CI 0.19-0.48]) [40-44]; grip strength (significant associations reported in all studies [45-47]); and gait speed [48]. Greater loss of arm lean mass was associated with accelerated loss of grip strength in a cohort of 1710 Afro-Caribbean men [49]. These findings are in agreement with our results from the Health ABC Study.

There are several potential mechanisms that may explain why longitudinal decreases in muscle mass, strength and BMD are correlated with one another in later life. First, the relationship between loss of muscle mass and strength may be bidirectional. Reductions in strength may result in declines in physical function and activity, leading to disuseinduced muscle wasting; simultaneously, declines in muscle mass and quality due to losses in fast-twitch muscle fibres, fat infiltration of skeletal muscle and increased inflammation may result in declines in strength and physical function [50]. Second, correlations between muscle mass and strength and BMD in older age are expected from both cellular and physiological perspectives. Cellular similarities include a shared mesenchymal stem cell origin between myoblasts and osteocytes [51]. Physiologically, reductions in strength lead to weaker forces on bone, resulting in greater bone resorption than formation according to the mechanostat theory [20, 52]. Finally, developmental, genetic, endocrine and lifestyle factors, such as smoking, physical activity and diet quality are established determinants of both muscle and bone aging [19], and may therefore contribute to correlations between declines in muscle and bone parameters.

A key strength of this study is the measurement of a wide range of musculoskeletal and body composition parameters in a single, well-characterised cohort. In contrast, studies which compare changes in musculoskeletal parameters across cohorts are likely to be limited because heterogeneous age ranges and nationalities of participants are likely to affect comparability of results. Another strength of the Health ABC Study is that parameters have been measured repeatedly over many follow-ups, enabling a comprehensive assessment of change.

This study has some limitations. Participants were free of mobility disability at baseline. This limits the generalisability of the findings to the wider population of communitydwelling older people in this age range and may have led to an underestimation of the magnitude of decline in these trajectories. Death and drop-outs during follow-up result in healthier participants remaining in the study who may be more likely to have slower rates of decline in musculoskeletal parameters. However, the inclusion of participants with two or more measures for examination of trajectories and calculation of percentage changes means that participants with short follow-ups are included in these analyses. Furthermore, the similarity of the trajectories for participants with observations at all time-points and those for participants with two or more repeated measures (eFigure 4 in Online Resource) suggests that drop-outs have only a small effect on the mean trajectories observed.

Our findings have important implications. Declines in later life were greater, and the proportion of variance at follow-up explained by baseline level was lower, for grip strength and gait speed compared with ALM, fat mass and hip BMD. This suggests that interventions that target body composition alone may be insufficient to also prevent the loss of muscle strength and function in this age group; these may require a broader range of intervention strategies, both to maximise peak levels in earlier life and to reduce agerelated declines in later life. These findings may inform the development of lifecourse intervention strategies to prevent or delay adverse changes in musculoskeletal aging.

Acknowledgements This work was supported by National Institute on Aging (NIA) Grants (R01AG027017, P30AG024827, T32AG021885 and K07AG033174); the Intramural Research program of the National Institutes of Health (N01AG62101, N01AG62103, N01AG62106 and R01AG028050); a National Institute of Nursing Research Grant (R01NR012459); the Medical Research Council (MRC_MC_ UU_12011/2 and MRC_MC_UP_A620_1015) and the University of Southampton, UK. Dr Fielding's participation was supported by the U.S. Department of Agriculture (USDA), under agreement No. 58-1950-4-003. Any opinions, findings, conclusions or recommendations expressed in this publication are those of the authors and do not necessarily reflect the view of the USDA. The authors thank the participants of the Health, Aging and Body Composition Study as well as members of the scientific and data collection teams.

Author Contributions LW conducted the statistical analysis and wrote the first draft of the manuscript; HES provided guidance regarding the statistical analysis and made extensive contributions to the content of the manuscript; NRF contributed to the literature review and the interpretation of the findings; EMD and CC designed the study; JAC, EJS and ABN were investigators of the Health ABC Study. All authors made substantial contributions to the manuscript and approved the final version.

\section{Compliance with Ethical Standards}

Conflict of interest $\mathrm{CC}$ reports personal fees (outside the submitted work) from Alliance for Better Bone Health, Amgen, Eli Lilly, GSK, Medtronic, Merck, Novartis, Pfizer, Roche, Servier, Takeda and UCB. EMD reports personal fees (outside the submitted work) from Pfizer Healthcare and from the UCB Discussion panel. RAF reports grants from National Institutes of Health (National Institute on Aging) and the USDA, during the conduct of the study; grants, personal fees and other from Axcella Health, other from Inside Tracker, grants and personal fees from Biophytis, grants and personal fees from Astellas, personal fees from Cytokinetics, personal fees from Amazentis, grants and personal fees from Nestle', personal fees from Glaxo Smith Kline, outside the submitted work. LDW, HES, NRF, JAC, EJS and ABN declare that they have no conflicts of interest.

Ethical Approval The study was approved by the institutional review boards at the University of Tennessee and the University of Pittsburgh. 
Human and Animal Rights All procedures performed in studies involving human participants were in accordance with the ethical standards of the institutional and/or national research committee and with the 1964 Helsinki declaration and its later amendments or comparable ethical standards.

Informed Consent Written, informed consent was provided by all participants.

Open Access This article is licensed under a Creative Commons Attribution 4.0 International License, which permits use, sharing, adaptation, distribution and reproduction in any medium or format, as long as you give appropriate credit to the original author(s) and the source, provide a link to the Creative Commons licence, and indicate if changes were made. The images or other third party material in this article are included in the article's Creative Commons licence, unless indicated otherwise in a credit line to the material. If material is not included in the article's Creative Commons licence and your intended use is not permitted by statutory regulation or exceeds the permitted use, you will need to obtain permission directly from the copyright holder. To view a copy of this licence, visit http://creativecommons.org/licenses/by/4.0/.

\section{References}

1. Vos T, Abajobir AA, Abate KH, Abbafati C, Abbas KM, AbdAllah F, Abdulkader RS, Abdulle AM, Abebo TA, Abera SF (2017) Global, regional, and national incidence, prevalence, and years lived with disability for 328 diseases and injuries for 195 countries, 1990-2016: a systematic analysis for the Global Burden of Disease Study 2016. Lancet 390:1211-1259

2. Beaudart C, Rizzoli R, Bruyère O, Reginster J-Y, Biver E (2014) Sarcopenia: burden and challenges for public health. Arch Public Health 72:45

3. Brown JC, Harhay MO, Harhay MN (2016) Sarcopenia and mortality among a population-based sample of communitydwelling older adults. J Cachexia Sarcopenia Muscle 7:290-298

4. Bruyère $\mathrm{O}$, Beaudart $\mathrm{C}$, Ethgen $\mathrm{O}$, Reginster $\mathrm{J}-\mathrm{Y}$, Locquet $\mathrm{M}$ (2019) The health economics burden of sarcopenia: a systematic review. Maturitas 119:61-69

5. Janssen I, Shepard DS, Katzmarzyk PT, Roubenoff R (2004) The healthcare costs of sarcopenia in the United States. J Am Geriatr Soc 52:80-85

6. Pinedo-Villanueva R, Westbury LD, Syddall HE, Sanchez-Santos MT, Dennison EM, Robinson SM, Cooper C (2019) Health care costs associated with muscle weakness: a UK populationbased estimate. Calcif Tissue Int 104:137-144

7. Cao L, Morley JE (2016) Sarcopenia is recognized as an independent condition by an international classification of disease, tenth revision, clinical modification (ICD-10-CM) code. J Am Med Dir Assoc 17:675-677

8. Dennison E, Mohamed MA, Cooper C (2006) Epidemiology of osteoporosis. Rheum Dis Clin North Am 32:617-629

9. Leboime A, Confavreux CB, Mehsen N, Paccou J, David C, Roux C (2010) Osteoporosis and mortality. Joint Bone Spine 77:S107-S112

10. Hernlund E, Svedbom A, Ivergård M, Compston J, Cooper C, Stenmark J, McCloskey EV, Jönsson B, Kanis JA (2013) Osteoporosis in the European Union: medical management, epidemiology and economic burden. Arch Osteoporos 8:136

11. St-Onge MP, Gallagher D (2010) Body composition changes with aging: the cause or the result of alterations in metabolic rate and macronutrient oxidation? Nutrition 26:152-155
12. Visser M, Langlois J, Guralnik JM, Cauley JA, Kronmal RA, Robbins J, Williamson JD, Harris TB (1998) High body fatness, but not low fat-free mass, predicts disability in older men and women: the Cardiovascular Health Study. Am J Clin Nutr 68:584-590

13. Bigaard J, Frederiksen K, Tjønneland A, Thomsen BL, Overvad K, Heitmann BL, Sørensen TI (2004) Body fat and fat-free mass and all-cause mortality. Obes Res 12:1042-1049

14. Flegal KM, Kit BK, Orpana H, Graubard BI (2013) Association of all-cause mortality with overweight and obesity using standard body mass index categories: a systematic review and meta-analysis. JAMA 309:71-82

15. Winter JE, MacInnis RJ, Wattanapenpaiboon N, Nowson CA (2014) BMI and all-cause mortality in older adults: a metaanalysis. Am J Clin Nutr 99:875-890

16. Bowman K, Atkins JL, Delgado J, Kos K, Kuchel GA, Ble A, Ferrucci L, Melzer D (2017) Central adiposity and the overweight risk paradox in aging: follow-up of 130,473 UK Biobank participants. Am J Clin Nutr 106:130-135

17. Bowman K, Delgado J, Henley WE, Masoli JA, Kos K, Brayne C, Thokala P, Lafortune L, Kuchel GA, Ble A (2016) Obesity in older people with and without conditions associated with weight loss: follow-up of 955,000 primary care patients. J Gerontol A Biol Sci Med Sci 72:203-209

18. Batsis JA, Villareal DT (2018) Sarcopenic obesity in older adults: aetiology, epidemiology and treatment strategies. Nat Rev Endocrinol 14:513-537

19. Curtis E, Litwic A, Cooper C, Dennison E (2015) Determinants of muscle and bone aging. J Cell Physiol 230:2618-2625

20. Patel A, Edwards M, Jameson K, Ward K, Fuggle N, Cooper C, Dennison E (2018) Longitudinal change in peripheral quantitative computed tomography assessment in older adults: the hertfordshire cohort study. Calcif Tissue Int 103:476-482

21. Auyeung TW, Lee SWJ, Leung J, Kwok T, Woo J (2014) Ageassociated decline of muscle mass, grip strength and gait speed: a 4-year longitudinal study of 3018 community-dwelling older Chinese. Geriatr Gerontol Int 14:76-84

22. Locquet M, Beaudart $\mathrm{C}$, Durieux N, Reginster J-Y, Bruyère $\mathrm{O}$ (2019) Relationship between the changes over time of bone and muscle Health in children and adults: a systematic review and meta-analysis. BMC Musculoskelet Disord 20:429

23. National Institute on Aging Introducing the Health ABC Study: The Dynamics of Health, Aging, and Body Composition. https ://healthabc.nia.nih.gov/. Accessed 4 October 2019

24. Taylor HL, Jacobs DR, Schucker B, Knudsen J, Leon AS, Debacker G (1978) A questionnaire for the assessment of leisure time physical activities. J Chronic Dis 31:741-755

25. Ainsworth BE, Haskell WL, Leon AS, Jacobs JD, Montoye HJ, Sallis JF, Paffenbarger JR (1993) Compendium of physical activities: classification of energy costs of human physical activities. Med Sci Sports Exerc 25:71-80

26. Taaffe DR, Simonsick EM, Visser M, Volpato S, Nevitt MC, Cauley JA, Tylavsky FA, Harris TB (2003) Lower extremity physical performance and hip bone mineral density in elderly black and white men and women: cross-sectional associations in the Health ABC Study. J Gerontol A Biol Sci Med Sci 58:M934-942

27. Kennedy T, Ohls J, Carlson S, Fleming K (1995) The healthy eating index: design and applications. J Am Diet Assoc 95:1103-1108

28. Hengeveld LM, Wijnhoven HA, Olthof MR, Brouwer IA, Harris TB, Kritchevsky SB, Newman AB, Visser M, Study HA (2018) Prospective associations of poor diet quality with long-term incidence of protein-energy malnutrition in community-dwelling older adults: the Health, Aging, and Body Composition (Health ABC) Study. Am J Clin Nutr 107:155-164 
29. Visser M, Fuerst T, Lang T, Salamone L, Harris TB (1999) Validity of fan-beam dual-energy X-ray absorptiometry for measuring fat-free mass and leg muscle mass. Health, aging, and body composition study-dual-energy X-ray absorptiometry and body composition working group. J Appl Physiol 87:1513-1520

30. Salamone LM, Fuerst T, Visser M, Kern M, Lang T, Dockrell M, Cauley JA, Nevitt M, Tylavsky F, Lohman TG (2000) Measurement of fat mass using DEXA: a validation study in elderly adults. J Appl Physiol 89:345-352

31. Goodpaster BH, Park SW, Harris TB, Kritchevsky SB, Nevitt M, Schwartz AV, Simonsick EM, Tylavsky FA, Visser M, Newman AB (2006) The loss of skeletal muscle strength, mass, and quality in older adults: the health, aging and body composition study. J Gerontol A Biol Sci Med Sci 61:1059-1064

32. Delmonico MJ, Harris TB, Visser M, Park SW, Conroy MB, Velasquez-Mieyer P, Boudreau R, Manini TM, Nevitt M, Newman AB, Goodpaster BH, Health Aging Body (2009) Longitudinal study of muscle strength, quality, and adipose tissue infiltration. Am J Clin Nutr 90:1579-1585

33. Ding J, Kritchevsky SB, Newman AB, Taaffe DR, Nicklas BJ, Visser M, Lee JS, Nevitt M, Tylavsky FA, Rubin SM, Pahor M, Harris TB (2007) Effects of birth cohort and age on body composition in a sample of community-based elderly. Am J Clin Nutr 85:405-410

34. Newman AB, Lee JS, Visser M, Goodpaster BH, Kritchevsky SB, Tylavsky FA, Nevitt M, Harris TB (2005) Weight change and the conservation of lean mass in old age: the Health, Aging and Body Composition Study. Am J Clin Nutr 82:872-878

35. Forbes GB (1999) Longitudinal changes in adult fat-free mass: influence of body weight. Am J Clin Nutr 70:1025-1031

36. Frederiksen H, Hjelmborg J, Mortensen J, Mcgue M, Vaupel JW, Christensen K (2006) Age trajectories of grip strength: crosssectional and longitudinal data among 8,342 Danes aged 46 to 102. Ann Epidemiol 16:554-562

37. Granic A, Davies K, Jagger C, Kirkwood TB, Syddall HE, Sayer AA (2016) Grip strength decline and its determinants in the very old: longitudinal findings from the Newcastle 85+ Study. PLoS ONE 11:e0163183

38. Newman AB, Sanders JL, Kizer JR, Boudreau RM, Odden MC, Zeki Al Hazzouri A, Arnold AM (2016) Trajectories of function and biomarkers with age: the CHS all stars study. Int J Epidemiol 45:1135-1145

39. Cawthon PM, Ewing SK, McCulloch CE, Ensrud KE, Cauley JA, Cummings SR, Orwoll ES (2009) Loss of hip BMD in older men: the osteoporotic fractures in men (MrOS) study. J Bone Miner Res 24:1728-1735

40. Liu-Ambrose T, Kravetsky L, Bailey D, Sherar L, Mundt C, Baxter-Jones A, Khan K, McKay H (2006) Change in lean body mass is a major determinant of change in areal bone mineral density of the proximal femur: a 12-year observational study. Calcif Tissue Int 79:145-151
41. Milliken L, Cussler E, Zeller R, Choi J-E, Metcalfe L, Going SB, Lohman TG (2009) Changes in soft tissue composition are the primary predictors of 4-year bone mineral density changes in postmenopausal women. Osteoporos Int 20:347-354

42. Arabi A, Baddoura R, El-Rassi R, Fuleihan GE-H (2012) PTH level but not $25(\mathrm{OH})$ vitamin $\mathrm{D}$ level predicts bone loss rates in the elderly. Osteoporos Int 23:971-980

43. Bleicher K, Cumming RG, Naganathan V, Travison TG, Sambrook PN, Blyth FM, Handelsman DJ, Le Couteur DG, Waite LM, Creasey HM (2011) The role of fat and lean mass in bone loss in older men: findings from the CHAMP study. Bone 49:1299-1305

44. Chen Z, Lohman TG, Stini WA, Ritenbaugh C, Aickin M (1997) Fat or lean tissue mass: which one is the major determinant of bone mineral mass in healthy postmenopausal women? J Bone Miner Res 12:144-151

45. Sirola J, Rikkonen T, Tuppurainen M, Honkanen R, Jurvelin J, Kröger H (2006) Maintenance of muscle strength may counteract weight-loss-related postmenopausal bone loss-a populationbased approach. Osteoporos Int 17:775-782

46. Sirola J, Rikkonen T, Tuppurainen M, Jurvelin J, Kröger H (2006) Association of grip strength change with menopausal bone loss and related fractures: a population-based follow-up study. Calcif Tissue Int 78:218-226

47. Sirola J, Tuppurainen M, Honkanen R, Jurvelin JS, Kröger H (2005) Associations between grip strength change and axial postmenopausal bone loss-a 10-year population-based followup study. Osteoporos Int 16:1841-1848

48. Kwon J, Suzuki T, Yoshida H, Kim H, Yoshida Y, Iwasa H, Sugiura M, Furuna T (2007) Association between change in bone mineral density and decline in usual walking speed in elderly community-dwelling japanese women during 2 years of followup. J Am Geriatr Soc 55:240-244

49. Forrest KY, Bunker CH, Sheu Y, Wheeler VW, Patrick AL, Zmuda JM (2012) Patterns and correlates of grip strength change with age in Afro-Caribbean men. Age Ageing 41:326-332

50. Westbury L, Fuggle N, Syddall HE, Duggal N, Shaw S, Maslin K, Dennison E, Lord J, Cooper C (2018) Relationships between markers of inflammation and muscle mass, strength and function: findings from the Hertfordshire Cohort Study. Calcif Tissue Int 102:287-295

51. Singer NG, Caplan AI (2011) Mesenchymal stem cells: mechanisms of inflammation. Annu Rev Pathol 6:457-478

52. Frost HM (2003) Bone's mechanostat: a 2003 update. Anat Rec A $275: 1081-1101$

Publisher's Note Springer Nature remains neutral with regard to jurisdictional claims in published maps and institutional affiliations. 